CASE REPORT

\title{
Endoglin germline mutation in a patient with hereditary haemorrhagic telangiectasia and dexfenfluramine associated pulmonary arterial hypertension
}

\author{
A Chaouat, F Coulet, C Favre, G Simonneau, E Weitzenblum, F Soubrier, M Humbert
}

Thorax 2004;59:446-448. doi: 10.1136/thx.2003.11890

Dexfenfluramine associated pulmonary arterial hypertension occurring in a patient with hereditary haemorrhagic telangiectasia related to a mutation within the endoglin gene is described. This report highlights the critical role of the TGF$\beta$ signalling pathway in this condition.

$\mathrm{P}$ ulmonary arterial hypertension (PAH) is defined as a group of diseases characterised by a progressive increase in pulmonary vascular resistance leading to right heart failure and ultimately to death. ${ }^{1}$ Familial cases segregate as an autosomal dominant trait with low disease gene penetrance. Mutations within the bone morphogenetic protein receptor type II gene (BMPR2), coding for a receptor of the transforming growth factor $\beta$ (TGF- $\beta$ ) superfamily, have been shown to underlie most familial cases of primary pulmonary hypertension $^{23}$ and at least $26 \%$ of so-called "sporadic" cases. ${ }^{4}$

Pulmonary arterial hypertension can also develop in patients with various associated conditions including hereditary haemorrhagic telangiectasia ${ }^{5}$ or exposure to anorectic agents such as fenfluramine derivatives. ${ }^{6}$ The frequency of $\mathrm{PAH}$ is evaluated at one in 10000 to one in 100000 patients with a history of fenfluramine derivatives intake. ${ }^{7}$ Conversely, since BMPR2 mutations have been detected in $9 \%$ of patients with fenfluramine or dexfenfluramine associated $\mathrm{PAH}$, associated environmental, epigenetic or genetic factors are required for the development of $\mathrm{PAH}^{7}$

Mutations in two genes encoding TGF- $\beta$ receptors (activin receptor-like kinase l (ALKl) and endoglin) underlie hereditary haemorrhagic telangiectasia, an autosomal dominant vascular dysplasia with abnormally dilated vessels forming mucosal and visceral telangiectasia. ${ }^{8}$ Approximately $25 \%$ of families affected in France and in the UK carry a known endoglin germline mutation. Trembath and colleagues $^{5}$ recently described cases of PAH in families affected by hereditary haemorrhagic telangiectasia and mutations of $A L K 1$ were identified in these subjects.

We describe a case of dexfenfluramine associated PAH occurring in a patient with hereditary haemorrhagic telangiectasia related to a mutation within the endoglin gene. This report highlights the critical role of the TGF- $\beta$ signalling pathway in this condition.

\section{CASE REPORT}

\section{Clinical findings}

A 34 year old woman was referred with a 3 year history of progressive dyspnoea on exertion. She had recurrent epistaxes and mucocutaneous telangiectasia and both symptoms were also observed in three first degree and five second degree relatives (fig 1), establishing the diagnosis of hereditary haemorrhagic telangiectasia. She had taken dexfenfluramine for a period of 10 months 3 years before the onset of symptoms. On admission, dyspnoea was present for mild exercise (functional class III of the New York Heart Association classification). Apart from signs of hereditary haemorrhagic telangiectasia, physical examination revealed a systolic murmur of tricuspid regurgitation. A diagnosis of PAH was established using the diagnostic strategy recommended by the report of the 1998 World Symposium on Primary Pulmonary Hypertension (fig 2). No evidence of hepatic or pulmonary arteriovenous malformation was found. Right heart catheterisation confirmed severe PAH with a mean pulmonary artery pressure of $46 \mathrm{~mm} \mathrm{Hg}$, a capillary wedge pressure of $5 \mathrm{~mm} \mathrm{Hg}$, and a cardiac index of $2.2 \mathrm{l} / \mathrm{min} \times \mathrm{m}^{2}$. There was no acute response to vasodilators and the patient was subsequently treated with continuous intravenous epoprostenol.

\section{Genetic studies}

Written informed consent for the genetic diagnosis was obtained from the patient, according to bioethical laws.

DNA was isolated from peripheral blood lymphocytes using a purification kit (QIAamp blood kit, Qiagen, Courtaboeuf, France). All coding exons of the endoglin, ALK1 and BMPR2 genes were sequenced by PCR amplification with intronic flanking primers and additional exonic primers when necessary. Primers were designed according to published sequences $^{910}$ and using the human genome sequence. Sequencing reactions were performed with the ABI Prism Big Dye terminator cycle sequencing kit and analysed on an ABI310 sequence analyser (both from Applied Biosystems, Foster City, CA, USA).

A single nucleotide deletion of guanine in the coding region of the endoglin gene was found 470 bases from the translation start site in exon 11 (del 470G, fig 3). This alteration results in a frame shift mutation responsible for premature termination of the protein at position 490. The truncated protein is predicted to lose at least the cytoplasm tail and the transmembrane region.

\section{DISCUSSION}

We describe dexfenfluramine associated PAH in a patient with hereditary haemorrhagic telangiectasia probably favoured by a mutation within the endoglin gene. A germline endoglin mutation was identified in this case, showing that both endoglin and ALKI can be involved in PAH and hereditary haemorrhagic telangiectasia. This provides confirmation that several components of the TGF- $\beta$ signalling pathway are involved in the pathophysiology of PAH. Moreover, since pulmonary hypertension occurred after a 10 month exposure to dexfenfluramine, it is likely that 


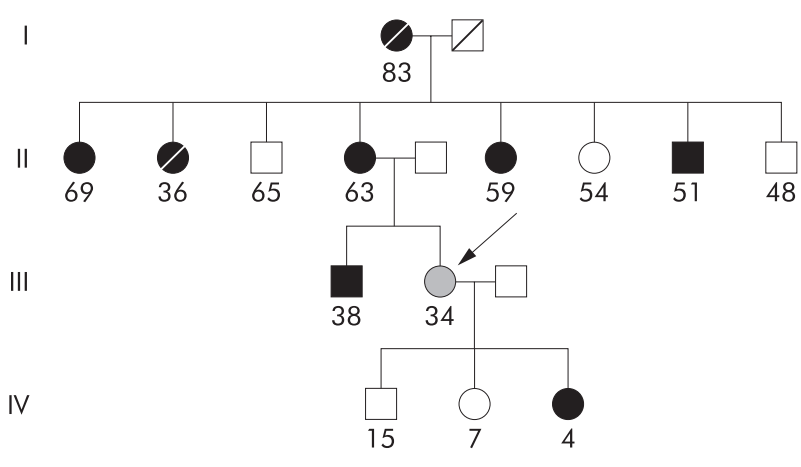

Figure 1 Pedigree of the family with coexisting pulmonary arterial hypertension and hereditary haemorrhagic telangiectasia. Squares denote male family members, circles female family members, hatched symbol member with both pulmonary arterial hypertension and hereditary haemorrhagic hypertension (arrow), black symbols members with hereditary haemorrhagic telangiectasia alone, and open symbols members unaffected by either condition.

exposure to appetite suppressants and endoglin mutation played a combined role in the development of the pulmonary vascular disease. ${ }^{67}$ Previous descriptions of hereditary haemorrhagic telangiectasia with PAH and the rare occurrence of pulmonary hypertension after exposure to dexfenfluramine suggest that the possibility of a fortuitous association is unlikely. The frequency of such an association calculated from the product of the estimated frequency of each disease would be between $10^{-9}$ and $10^{-8} .^{78}$

$B M P R 2, A L K 1$ and endoglin belong to the TGF- $\beta$ superfamily signalling pathway. The TGF- $\beta$ signalling pathway has several functions including embryonic angiogenesis, regulation of cell proliferation and differentiation, and extracellular matrix deposition. It consists of a cascade of molecule phosphorylation after binding of the ligand at the cell membrane. After ligand binding a type II receptor phosphorylates and aggregates with a type I receptor and, in some cells (including endothelial cells and vascular smooth muscle cells) with endoglin (also called a type III receptor). ${ }^{11}$ These receptors have serine/threonine kinase activity and phosphorylate Smad proteins which, in cooperation with coSmads, penetrate the nucleus and activate or inhibit the transcription of target genes. ${ }^{11}$ The complexity and versatility of the TGF- $\beta$ pathway comes from the number of molecules belonging to each class in the pathway, which differs from cell to cell.

Heterozygous mutations are responsible for a $50 \%$ decrease in the level of expression of the disease gene in target cells such as endothelial or vascular smooth muscle cells, and this was observed in cells and tissues of patients bearing endoglin mutations. ${ }^{12}$ These latter data and the in vitro expression analysis of endoglin mutants suggest that haploinsufficiency is the responsible mechanism in most cases. ALKl or endoglin haploinsufficiency is responsible for hereditary haemorrhagic telangiectasia with high penetrance, in contrast to the rare occurrence of $\mathrm{PAH}$ in patients with $A L K 1$ mutations and to the low penetrance of BMPR2 mutations for PAH. It is therefore speculated that additional factors are required to explain the occurrence of a secondary disease with abnormal proliferation of vascular smooth muscle cells and endothelial cells in pulmonary arterial lesions. In the case reported here the additional factor could be exposure to dexfenfluramine.

TGF- $\beta$ has an inhibitory role in cell proliferation, particularly on vascular smooth muscle cells. Two growth abnormalities have been described for pulmonary artery smooth muscle cell in vitro in patients with primary pulmonary hypertension. The first is a paradoxical proliferative effect of

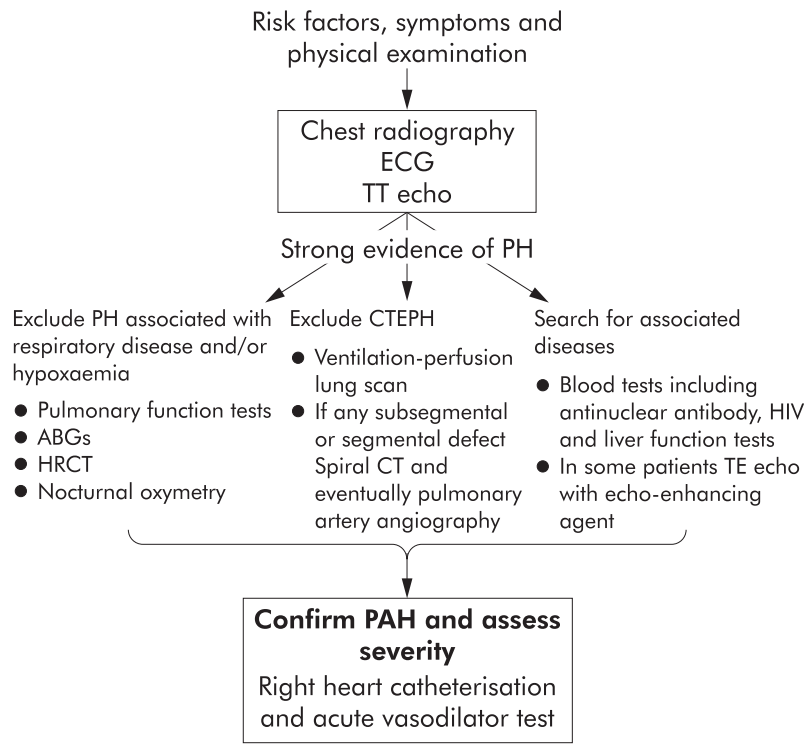

Figure 2 Diagnostic strategy in patients with suspected pulmonary arterial hypertension (PAH). ECG = electrocardiogram;

$\mathrm{TT}=$ transthoracic; $\mathrm{PH}=$ pulmonary hypertension; $\mathrm{ABGs}=$ arterial blood gases, $\mathrm{HRCT}=$ high resolution thoracic computed tomography, $\mathrm{TE}=$ transoesophageal.

\section{A}

.CACCATCGAGCCGGGGCAGCAG AGCTITGT GC

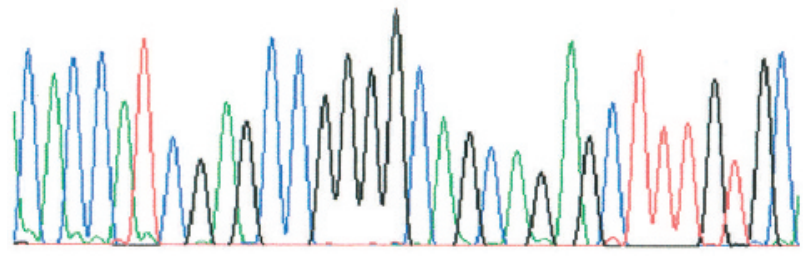

B

$C A C C A T C G A G C C G G G \mathbf{N} \mathbf{N}$ A A A A T T T MG G G

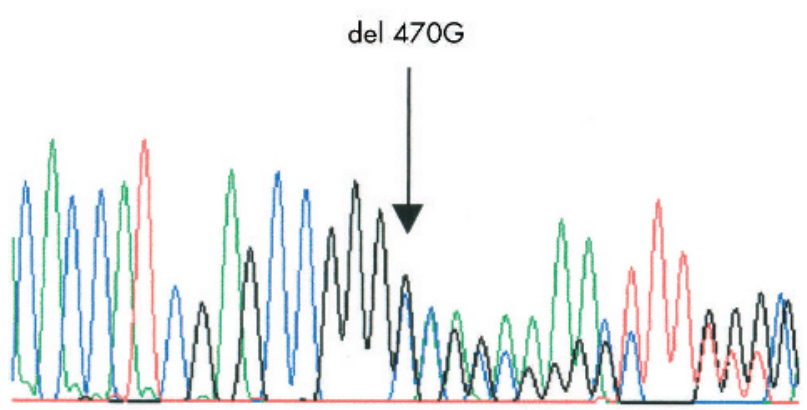

Figure 3 Sequencing of exon 11 of the endoglin gene. A single nucleotide heterozygous deletion in the coding region 470 bases from the translation start site in exon 11 was found. This deletion predicts a frameshift and a premature stop codon at position 490 . The location of the guanine deletion (del $470 \mathrm{G}$ ) is indicated by a vertical arrow. A and $B$ templates correspond to the sequence of an individual without the mutation and the sequence of the proband's exon 11, respectively. 
TGF- $\beta$ in pulmonary artery smooth muscle cells from patients with primary pulmonary hypertension in contrast to control cells in which TGF- $\beta$ has a growth inhibitory effect. ${ }^{13}$ The second is an excessive uptake of serotonin in pulmonary artery smooth muscle cells from patients with primary pulmonary hypertension compared with controls. ${ }^{14}$ The vascular smooth muscle cells from patients with primary pulmonary hypertension also exhibit increased thymidine incorporation in response to serotonin, a known proliferative agent for these cells (an effect abolished by serotonin transporter inhibitors such as fluoxetine) and associated with increased expression of serotonin transporters. ${ }^{14}$ Fenfluramine-like medications contribute to the development of PAH by increasing circulating serotonin levels. They may also act as serotonin transporter substrates to produce the same effect as serotonin, or they may alter serotonin transporter expression. An alternative hypothesis could be related to the inhibitory effect of dexfenfluramine on voltage gated potassium channels which is responsible for an increase in the intracellular calcium concentration. ${ }^{15} \mathrm{~A}$ chronic increase in the intracellular calcium concentration may subsequently promote cell proliferation. In our patient exposure to dexfenfluramine may have triggered the pulmonary vascular disease.

Under normal conditions the balance between inhibitory and stimulatory cell growth systems of vascular cells is maintained by antagonistic factors such as TGF- $\beta$, on one hand, and serotonin on the other. Disturbance of the equilibrium can originate in mutations of BMPR2, ALK1 or-as suggested by the case presented here-in mutations of endoglin. Our results are consistent with those of $\mathrm{Du}$ and colleagues $^{16}$ who showed that the TGF- $\beta$ cell signalling pathway could be involved in all forms of pulmonary hypertension. The finding in our case adds endoglin mutations to other confirmed or suspected genetic predispositions to $\mathrm{PAH}$. It also suggests that all environmental risk factors for $\mathrm{PAH}$ must be avoided in patients with hereditary haemorrhagic telangiectasia.

\section{ACKNOWLEDGEMENTS}

The authors thank Dr B Thomas for her critical reading of the manuscript.

\footnotetext{
Authors' affiliations

A Chaouat, C Favre, E Weitzenblum, Service de Pneumologie, Hôpital de Hautepierre, Strasbourg, France

F Coulet, F Soubrier, Laboratoire de Génétique Moléculaire, Hôpital Tenon, Assistance Publique-Hôpitaux de Paris, France

G Simonneau, M Humbert, UPRES EA2705, Service de Pneumologie et Réanimation Respiratoire, Hôpital Antoine-Béclère, Université Paris-Sud, Assistance Publique-Hôpitaux de Paris, Clamart, France
}

Correspondence to: Dr A Chaouat, Service de Pneumologie, Hôpital de Hautepierre, Avenue Molière, 67098 Strasbourg Cedex, France; ari.chaouat@chru-strasbourg.fr

This study was supported by grants from Legs Poix, Université Paris-Sud, AFM and INSERM

Received 19 June 2003

Accepted 14 August 2003

\section{REFERENCES}

1 Rubin L. Primary pulmonary hypertension. N Engl J Med 1997;336:111-7.

2 Lane KB, Machado RD, Pauciulo MW, et al. Heterozygous germline mutations in a TGF-beta receptor, BMPR2, are the cause of familial primary pulmonary hypertension. The International PPH Consortium. Nat Genet 2000;26:81-4.

3 Deng Z, Morse JH, Slager SL, et al. Familial primary pulmonary hypertension (gene $\mathrm{PPH} 1$ ) is caused by mutations in the bone morphogenetic protein receptor-ll gene. Am J Hum Genet 2000;67:737-44.

4 Thomson JR, Machado RD, Pauciulo MW, et al. Sporadic primary pulmonary hypertension id associated with germline mutations of the gene encoding BMPR-II, a receptor member of the TGF-beta family. J Med Genet 2000;37:741-5

5 Trembath R, Thomson JR, Machado RD, et al. Clinical and molecular genetic features of pulmonary hypertension in patients with hereditary hemorrhagic telangiectasia. N Engl J Med 2001;345:325-34.

6 Abenhaim L, Moride Y, Brenot F, et al. Appetite-suppressant drugs and the risk of primary pulmonary hypertension. N Engl J Med 1996;335:609-16.

7 Humbert M, Deng Z, Simonneau G, et al. BMPR2 germline mutations in pulmonary hypertension associated with fenfluramine derivatives. Eur Respir J 2002;20:518-23.

8 Shovlin $\mathrm{CL}$, Letarte $\mathrm{M}$. Hereditary hemorrhagic telangiectasia and pulmonary arteriovenous malformations: issues in clinical management and review of pathogenic mechanisms. Thorax 1999;54:714-29.

9 Attisano L, Carcamo J, Ventura F, et al. Identification of human activin and TGF beta type I receptors that form heteromeric kinase complexes with type II receptors. Cell 1993;75:671-80.

10 McAllister KA, Grogg KM, Johnson DW, et al. Endoglin, a TGF-beta binding protein of endothelial cells, is the gene for hereditary haemorrhagic telangiectasia type 1. Nat Genet 1994;8:345-51.

11 Barbara NP, Wrana JL, Letarte M. Endoglin is an accessory protein that interacts with the signaling receptor complex of multiple members of the transforming growth factor-beta superfamily. J Biol Chem 1999:274:584-94.

12 Pece-Barbara N, Cymerman U, Vera S, et al. Expression analysis of four endoglin missense mutations suggests that haploinsufficiency is the predominant mechanism for hereditary hemorrhagic telangiectasia type 1 . Hum Mol Genet 1999;8:2171-81.

13 Morrell NW, Yang X, Upton PD, et al. Altered growth responses of pulmonary artery smooth muscle cells from patients with primary pulmonary hypertension to transforming growth factor-beta[1] and bone morphogenetic proteins. Circulation 2001;104:790-5.

14 Eddahibi S, Humbert M, Fadel E, et al. Serotonin transporter overexpression is responsible for pulmonary artery smooth muscle hyperplasia in primary pulmonary hypertension. J Clin Invest 2001;108:1141-50.

15 Archer S, Rich S. Primary pulmonary hypertension. A vascular biology and translational research "work in progress". Circulation 2000;102:2781-91.

16 Du L, Sullivan CC, Chu D, et al. Signaling molecules in nonfamilial pulmonary hypertension. N Engl J Med 2003;348:500-9. 